\title{
LXXXIV. An account and explanation of some remarkable results obtained during a course of electro-magnetic experiments
}

\section{Rev. J.W. MacGauley}

To cite this article: Rev. J.W. MacGauley (1836) LXXXIV. An account and explanation of some remarkable results obtained during a course of electro-magnetic experiments, Philosophical Magazine Series 3, 9:56, 452-456, DOI: 10.1080/14786443608649040

To link to this article: http://dx.doi.org/10.1080/14786443608649040

曲 Published online: 01 Jun 2009.

Submit your article to this journal $[\pi$

Џll Article views: 2

Q View related articles $₫$ 


\section{The Rev. J. W. MacGauley on some remarkable Results}

explained by the fact made known by Mr. Faraday, that air when heated becomes a conductor. But that could not apply here, for in the first place, it is not air at all that is the medium of conduction, it is liquid iodine; and in the second, on melting the iodine and inverting the tube the conduction is suspended.

Dr. Apjohn now suggested that the iodine at the temperature required for its liquefaction might act on the platinum, and that an ioduret of platinum thus formed would conduct.

But iodine does not act on platinum at $225^{\circ}$ Fahr., and $225^{\circ}$ is the point at which iodine fuses.

This I stated at the time the objection was made, and since my return $I$ have accurately weighed a piece of platinum wire, and allowed iodine to act on it for half an hour, at and above the point of fusion; when on weighing again, the platinum wire was found to have lost nothing ; so that Dr. Apjohn's objection thus loses its weight, no ioduret having been formed.

The conducting power of iodine, atmospheric air, and some other substances when heated, and their non-conducting when cold, adds, I think, an argument in favour of that theory which considers electricity to be but an action of matter; and heat and electricity to be but modifications of each other.

Castle Douglas, Oct. 3, 1836.

J MMES INGLIS.

LXXXIV. An Account and Explanation of some remarkable Results obtained during a Course of Electro-Magnetic Experiments. By the Rev.J. W. MACGAULEY*.

I $\mathrm{T}$ is impossible not to remark that the electro-magnetic helix seems to increase the power of a given battery, for the brilliancy of the spark increases with the magnitude of the apparatus. I expected that such an intensity might be given by a very powerful electro-magnet, as that a small galvanic arrangement and a single circle might be made to communicate a considerable shack. I coiled nearly 2000 feet of copper wire, in ten helices, upon a bar of soft iron, during the experiments I was making preparatory to the construction of a large and greatly improved machine on the principle which I exhibited last year (1835) to the British Association, and which is now nearly completed: from this magnet I obtained a powerful shock.

It is not necessary to detail a great variety of arrangements adopted and results obtained; among others I came to the following conclusions :

* Read before the Royal Dublin Society on June 14th; and now communicated by the Author. 
1st. That the spark and shock obtained from an electromagnet, on breaking battery communication, are not the spark and shock of the battery nor of the electro-magnet, but, most probably, the electricity induced on the wire of the helix by the electricity of the battery, or, if it be true that a current passes along the wire, the electricity intercepted in its passage from the copper to the zinc.

2nd. That the spark and shock do not depend, except within certain limits, on the size of the battery.

3rd. That they confirm what I ventured to assert at the last meeting of the British Association (1835) on the nature of magnetism.

4th. That the real power of the battery is not increased but diminished by the electro-magnetic, or rather, electro-galvanic helix.

1st. The spark and shock (the latter of which I do not recollect to have seen remarked before,) obtained with an electro-magnet on breaking battery communication, are not the spark or shock of the battery, for neither one nor the other can exist until after battery communication is actually broken. Again, if they arise from the battery, to receive the shock it would be necessary to form a part of the communication between the copper and zinc. This, however, is not required; it is necessary only to form a part of the communication between the extremities of the helix, or between one extremity of the helix and either the copper or zinc of the battery. Neither does the shock or spark arise from the influence of the bar of soft iron inclosed in the helix : on the contrary, the retention of magnetism in the bars, either from the nature of its iron or the action of a keeper, will proportionably diminish the effect; and I have no doubt that if a large portion of magnetism were retained in a powerful electro-magnet by the keeper, and the keeper were torn off with violence from the magnet, a shock and spark would be perceived at the moment of disruption, which, together with those obtained when battery communication was broken, would form a spark and shock exactly equal to what were obtained had there been no retention of magnetism by the keepers when battery communication was interrupted.

Of the apparatus submitted to the Society for the purpose of demonstrating the facts contained in this paper by experiment, the part to which it was desired more particularly to direct attention consisted of 588 feet of copper wire, No. 13, coiled in seven helices of 84 feet each, on a thin brass tube, $5 \frac{1}{4}$ inches in length, $\frac{3}{4}$ internal diameter, having discs of brass, 4 inches in diameter, attached to its extremities. The tube 


\section{\$54 The Rev. J. W. MacGauley on some remarkable Results}

and discs were intended merely as a convenient means of coiling the wire and submitting bars of iron or of steel to the action of the helix. The corresponding extremities of the coils were soldered to two thick pieces of copper wire, which were made to dip respectively into two cups of mercury, forming a connexion between the poles and a calorimotor 1 foot square, double cell, charged with 400 drachms of water and 12 of muriatic acid. Wires lead from the same cups of mercury to vessels containing a solution of common salt, into which the hands are dipped for the purpose of obtaining a shock when battery connexion is broken. Though the wire, for convenience, is coiled upon brass, it is immaterial how it is arranged. I have thrown it into a heap, and believe the effect was equally powerful.

The spark and shock must be produced after battery communication is broken, because while it exists, every electrical effect must be prevented by the helix, as it affords a good conducting communication between the copper and zinc of the battery. Inclosing a bar of soft iron in the helix diminishes the effect.

2nd. The size of the battery, only within certain limits, affects the spark and shock. In constructing a galvanic helix, or a system of such helices, it is evident that the length of. the wire must be limited, on account of its imperfect conducting power. We must therefore, to produce a considerable effect, multiply the helices : on the other hand, if the battery be very small, a minute subdivision of its electricity anong so many wires may render the portions in each insufficient for any considerable disturbance of electrical equilibrium. The number of the coils and their lengths must therefore be regulated by the size of the battery and the conducting power of the wire.

3rd. Those properties of the electro-galvanic helix are strongly confirmatory of the theory I ventured to advance before the British Association on the nature of magnetism: "That its existence does not depend on the continuance of electrical currents; that continued electrical currents are not the consequence of magnetization ; and that magnetism is mere electrical excitement." For if electrical currents were essentially connected with magnetism, and if we can obtain a shock and spark - the acknowledged indications of a current by a simple helix - how much more should we obtain these indications when both causes are simultaneously in action, either of which, of itself, were sufficient for their production! Yet the existence of magnetism within the helix proportionably injures its effect. Magnetism is merely induced electricity, for it is 
produced by the action of an excited helix. The action of an excited body is the production of an opposite excitement on any body in its proximity, which induction increases its own capacity for electricity. Supposing magnetized substances to be merely modified instances of this seemingly, universal law, all their properties may easily be explained.

4th. The power of the battery is not increased, but diminished, by the helix; for, after passing through one helix, its power of exciting another is lessened, nor will it affect a galvanometer so much. If it were increased, judging by the spark and shock, and supposing these to arise from such increase, it ought to have acquired an intensity which would easily carry it through any length of wire.

When 400 drachms of water and 12 of muriatic acid were used, the effect was transitory; but the spark was very brilliant with the belix alone, less brilliant with a magnet having 12 feet more wire than the helix, less still with a smaller magnet. The shock with the helix was stronger than with the larger magnet; but when 400 drachms of water, 8 of sulphuric acid, and 4 of nitric acid were used, the spark from the helix remained the most brilliant, but the shock from the magnet became stronger than from the helix. To get a shock at a maximum from the helix, contact must be rapidly broken; from the magnet, slowly. The magnet had 600 feet of u ire coiled in three helices; the helix 588 feet in seven coils. The shock was considerably increased when two persons dipped their bands into the vessels containing the solution of salt; at the same time each received a greater shock than when only one person formed the communication.

If the mercury be not clean, or if some of the battery charge be found upon its surface, neither shock nor spark will be obtained, because as soon as the wire leaves the mercury, contact for the battery, as its electricity is of very low tension, ceases; but the other fluid will conduct away the electricity, from whence arise the shock and spark. If one extremity of the helix, or one wire of the battery, be lifted out of the mercury in contact with the wire leading from the same cup to the solution of salt, no shock will be felt.

A very cheap, permanent, and convenient apparatus, on the same principle is that submitted to the Society, may be constructed; one which would bear to the galvanic battery of a single circle the same relation as the Leyden jar to the electrical machine. Like the Leyden jar, jt may be made a magazine of power, realy to be exerted on any object the experimenter may desire; but it is not frail and perishable, does not clemand much care nor attention, does not depend on the 
state of the atmosphere for its efficiency, nor require almost anv expense it produce or continue its actions.

To construct it, however, on a large scale, a considerable quantity of wire, covered with an insulating substance, is required. The covering of the wire is at present, I believe, expensive, but a machine I constructed for the purpose, which leaves nolking to the care or skill of the operator, almost nothing to his labour, and which may be applied to many branches of manufacture, has changed what would otherwise be troublesome and laborious into the work of a few moments. Some judgement may be formed of the rapidity of its execution when I mention that very lately I covered with it 20,000 feet of wire of various diameters ; and of the exactness with which it covers it, by the nearly 1300 feet employed in the apparatus submitted to the Society.

79, Marlborough Street, Dublin, June 16,1836.

\section{On the Art of Glass-Painting. By A Corrispondent.}

$A \mathrm{~S}$ the accounts to be found in various works respecting this curious art are by no means satisfactory or complete, I have thought that a few observations on the subject, comprising a concise account of the processes employed, both in ancient and modern times, night be deemed of sufficient interest to obtain a place in the Lond. and Edinb. Philosophical Magazine.

It is a singular fact, that the art of glass-painting, practised with such success during former ages from one end of Europe to the other, should gradually have fallen into such disuse, that in the beginning of the last century it came to be generally considered as a lost art*. In the course of the eighteenth century, however, the art again began to attract

* [Our Correspondent will doubtless be glad to learn that a very able and interesting work on Glass-Painting has lately been published at Ronen, entitled, " Essai Historique et Descriptif sur la Peinture sur Verre ancienne et nioderne, et sur les Vitraux les plus remarquables de quelques monumens Français et étrangers; suivi de la Biographie des plus célebres PeintresVerriers: Par E. H. Langlois, du Pont-de-l'Arche, orné de Planches dessinées et gravées par Mademoiselle Esperance Langlois, 1839." The beautiful and curious windows of the churches of St. Godard, the Cathedral, St. Ouen, St. Patrice, and St. Vincent in Rouen have been copied by Mademoiselle Langlois with great spirit, skill and faithfuness.

M. Langlois disproves the notion ("l'aveugle préjugé"), that the art had been lost, p. 193; and states that this error was more unaccuntable in England, where, according to one of the memoirs of M. Al. Brongniart, a number of the finest windows were painted from 1616 to 1700 , and by Jervis Forrest up to 1785 . - R. 'T.] 